Decomposing wage residuals: Unmeasured skill or statistical artifact?

Wing Suen

Journal of Labor Economics; Jul 1997; 15, 3; ABI/INFORM Global

pg. 555

\title{
Decomposing Wage Residuals: Unmeasured Skill or Statistical Artifact?
}

\author{
Wing Suen, University of Hong Kong
}

The decomposition of wage residuals into standard deviation and percentile ranks can be misleading because the two measures are not necessarily independent. With rising wage inequality, the mean percentile rank of low-wage groups will rise simply because more dispersed distributions have thicker tails. This interpretation is consistent with the observed stability of gender and racial wage gaps. In contrast, the unmeasured skill interpretation of wage residuals would predict widening wage gaps in the face of rising wage inequality, unless one posits an increase in the level of unobserved skill for women and blacks.

\section{Introduction}

In two influential papers, Juhn, Murphy, and Pierce $(1991,1993)$ introduce an innovative method of decomposing residual wage differentials among groups of workers. Under a traditional wage decomposition (e.g., Blinder 1973; Oaxaca 1973), the wage gap between two groups of workers is explained by two sets of factors: (1) differences in average observable demographic characteristics and (2) differences in estimated returns associated with those characteristics. The residual wage differential after accounting for these factors is just that: a residual. Juhn et al.'s innovation is a method of further decomposing the residual differential based on percentile rankings. Roughly, each worker is assigned a percentile rank in the residual wage distribution. Changes in the residual differential

I thank Yoram Barzel and Shelly Lundberg for constructive comments.

[Journal of Labor Economics, 1997, vol. 15, no. 3, pt. 1]

(C) 1997 by The University of Chicago. All rights reserved. 0734-306X/97/1503-0007\$02.50 
between two groups are then decomposed into (3a) changes in the difference in their mean percentile ranks and ( $3 b$ ) changes in the dispersion of the residual wage distribution. Factor $3 \mathrm{a}$ is then interpreted as changes in the level of unmeasured skill, while factor $3 \mathrm{~b}$ is interpreted as changing returns to skill. As the profession's interest in the changing wage structure and rising wage inequality grows, Juhn et al.'s new method and its interpretation have gained acceptance quickly: Goldin and Margo (1992) and Margo (1995) adopt this method in their historical analysis of the changing U.S. wage structure, Blau and Kahn $(1992,1993)$ use the method to interpret international differences as well as secular changes in the gender pay gap, and LaLonde and Topel (1992) use the decomposition to study the assimilation of U.S. immigrants.

This article contends that interpreting the decomposition as prices and quantities of unmeasured ability is subject to bias. Juhn et al.'s method uses the standard deviation of residual wages to measure the price of skill and the average percentile rank to measure the quantity. Such a decomposition is unbiased only when percentile ranks are independent of the standard deviation. However, more dispersed distributions have thicker tails. For any fixed wage near the lower (upper) end of the distribution, its percentile ranking will rise (fall) with an increase in the dispersion of the wage distribution. As an extreme example, suppose male wages were concentrated at 1 (with zero variance) and female wages were concentrated at .7. The mean percentile rank of female wages in the (collapsed) male wage distribution is 0 . When male wages become more dispersed - say, they are distributed uniformly between 0 and 2-the mean percentile rank of female wages rises to .35 . In a regime of rising wage inequality, Juhn et al.'s method is then bound to find rising returns to "skill" and falling differences in the levels of such "skill," even when there is no change in either prices or quantities.

Holding the unobserved skills of women (or blacks) constant, an increase in the price of skills would result in a widening gender (or racial) wage gap. In the United States, however, the female earnings gap narrowed steadily and the racial earnings gap remained relatively stable during the 1980s, a period when the degree of wage dispersion increased substantially. To justify this observation, one has to posit that the price of (unobserved) skills has risen while the level of (unobserved) skills of women or blacks has also risen. Similarly, it has been observed that the female wage gap is greater in the United States than in other European countries, even though women in the United States have a higher mean percentile rank in the residual wage distribution. To justify this, one has to argue that the price of (unobserved) skills is higher in the United States and that women in the United States have greater (unobserved) skills than women in Europe. The statistical interpretation of wage residuals proposed here, however, offers a more direct and parsimonious expla- 
nation of the observed negative relationship between changes in wage dispersion and changes in mean percentile ranks: percentile ranks for lowwage groups rise because more dispersed distributions have thicker tails.

In the interpretation of wage differentials, a decomposition that yields falling differences in "unmeasured skill" is taken to indicate progress on the part of the minority group, while rising "price of skill" is taken to be the result of economy-wide factors. As a measure of the progress of disadvantaged groups, researchers often compute the hypothetical fall in wage differential due to the falling gap in skill had the price of skill not risen. If the alternative interpretation of residual decomposition proposed here is correct, such a procedure is unsound: there would be no falling gap in percentile rank ("skill") had the wage dispersion ("price of skill") not risen.

\section{Two Models of Wage Residuals}

Consider a wage equation for two groups of individuals (say, men and women):

$$
Y_{i t}=X_{i t} \beta_{t}+u_{i t}
$$

where $\log$ wage, $Y$, is regressed on observable characteristics (excluding gender), $X$.

The gender wage gap can be written as

$$
G_{t}=\left(X_{F t}-X_{M t}\right) \beta_{t}+\left(u_{F t}-u_{M t}\right)
$$

where the subscript $F t(M t)$ denotes the average of the female (male) values. Using $\Delta Z_{t}$ to denote $Z_{t}-Z_{s}$, the change in the gender pay gap between years $t$ and $s$ is

$$
\Delta G_{t} \approx \beta_{t} \Delta\left(X_{F t}-X_{M t}\right)+\left(X_{F t}-X_{M t}\right) \Delta \beta_{t}+\Delta\left(u_{F t}-u_{M t}\right)
$$

The first two terms correspond to the first two factors mentioned in the introduction (i.e., difference in mean endowments and difference in returns to endowments), and the last term corresponds to the change in residual wage gap.

The interpretation of the residual wage gap depends on the interpretation of $u$. For example, unexplained differences in wage rates between men and women could be due to differences in unobservable skills or to labor market discrimination. To encompass both possibilities, let

$$
u_{i t}=\sigma_{i} \theta_{i t}+\delta_{i t}
$$


Here, $\theta_{t i}$ is a random variable with mean $s_{F t}$ if individual $i$ is female, and it is distributed with mean $s_{M t}$ if $i$ is male. The variance of $\theta_{i t}$ is normalized to one. The term $\delta_{i t}$ is a constant that is equal to 0 for men and to $-d$ for women.

Two models of the wage gap can be subsumed under the general model in equation (4). Under the unobservable skills interpretation of the wage gap, $\theta_{i t}$ represents some unidimensional measure of labor market ability and $\sigma_{t}$ represents the price of such ability. In the polar case, the discrimination factor $d$ is assumed to be zero and all systematic differences in male and female wages arise from the assumption that mean skills are different between the sexes; that is, $s_{F t}<s_{M t}$. On the other extreme, the pure discrimination model of the wage gap assumes that $d$ is positive and there is no difference in mean unobserved skills; that is, $s_{F i}=s_{M_{i}}$.

Let $\Delta R_{t}$ represent the change in residual pay gap; that is, $\Delta R_{t}=\Delta\left(u_{F t}\right.$ $\left.-u_{M_{i}}\right)$. Using the general model of wage residuals specified in equation (4) above, $\Delta R_{t}$ can be decomposed into two components:

$$
\Delta R_{t} \approx \sigma_{i} \Delta\left(s_{F t}-s_{M t}\right)+\left(s_{F t}-s_{M t}\right) \Delta \sigma_{t} .
$$

Notice that the discrimination term $d$ drops out because it is assumed to be constant over time.

The decomposition of residuals shown in equation (5) is valid regardless of the interpretation of wage residuals one adopts. However, such a decomposition cannot be implemented because $\theta_{i t}$ (and hence $s_{F t}$ and $s_{M t}$ ) cannot be directly observed. In practice, the empirical implementation of this decomposition is based on the distribution of the residuals from the wage regression. More specifically, $\theta_{i t}$ is measured by the percentile rank of individual $i$ 's residual in the male residual wage distribution, and $\sigma_{t}$ is measured by the standard deviation of the male residual wage distribution. Since $u_{i t}=\sigma_{t} \theta_{i t}+\delta_{i t}$, substituting the rank of $u_{i t}$ for $\theta_{i t}$ is appropriate only when $\delta_{i t}$ is zero. The empirical implementation of wage residual decomposition therefore implicitly assumes that labor market discrimination is unimportant.

If the male residual wages are distributed normally with mean $u_{M t}$ and standard deviation $\sigma_{t}$, then the empirical decomposition of the residual wage gap is given by

$$
\begin{aligned}
\Delta R_{t} \approx & \sigma_{t} \Delta\left[E_{F t} \Phi\left(\left(u-u_{M t}\right) / \sigma_{t}\right)-E_{M t} \Phi\left(\left(u-u_{M t}\right) / \sigma_{t}\right)\right] \\
& +\left[E_{F t} \Phi\left(\left(u-u_{M t}\right) / \sigma_{t}\right)-E_{M t} \Phi\left(\left(u-u_{M t}\right) / \sigma_{t}\right)\right] \Delta \sigma_{t} .
\end{aligned}
$$

\footnotetext{
${ }^{1}$ Under the pure discrimination story, $\theta_{i t}$ could alternatively be interpreted as measurement error. The important assumption is that the mean of $\theta_{i t}$ does not differ between men and women.
} 
Here $E_{F t}\left(E_{M t}\right)$ denotes the average of the female (male) values over $u$. The decomposition is only approximate because the normal cumulative distribution function transformation is nonlinear. ${ }^{2}$ To simplify the exposition, let $u_{F t}$ be the mean of the female wage residuals, and assume $E_{F_{t}} \Phi(\cdot)$ $\approx \Phi\left[\left(u_{F t}-u_{M t}\right) / \sigma_{t}\right] .^{3}$ Also note that men will have an average rank of $50 \%$ in the male wage distribution; that is, $E_{M_{t}} \Phi(\cdot)=.5$. Equation (6) can then be rewritten as

$$
\begin{aligned}
\Delta R_{t} \approx & \sigma_{t} \Delta \Phi\left(\left(s_{F t}-s_{M t}\right)-\left(d / \sigma_{t}\right)\right) \\
& +\left[\Phi\left(\left(s_{F_{t}}-s_{M t}\right)-\left(d / \sigma_{t}\right)\right)-.5\right] \Delta \sigma_{t} .
\end{aligned}
$$

Juhn et al. (1993) demonstrate convincingly that the U.S. wage structure in the 1980s showed a marked increase in $\sigma_{t}$. During the same period, a decomposition of the female-male wage differential (Blau and Kahn 1993 ) indicates that the first term in equation (7) is positive while the second term is negative. It is tempting to conclude that the positive term is due to the narrowing gap in the level of unmeasured skill, while the negative term is due to the effect of rising prices on the differential skill between groups. For such a decomposition of wage residuals to be meaningful, however, changes in $\Phi\left[\left(u_{F t}-u_{M t}\right) / \sigma_{t}\right]$ and in $\sigma_{t}$ should be independent. Such would be the case if $d=0$; for then equation (7) can be simplified to

$$
\Delta R_{t} \approx \sigma_{t} \Delta \Phi\left(s_{F_{t}}-s_{M t}\right)+\left[\Phi\left(s_{F_{t}}-s_{M t}\right)-.5\right] \Delta \sigma_{t} .
$$

The first term in equation (8) will indeed correspond to the change in mean skills, and the second term will correspond to the change in the price of skills.

Consider, however, the pure discrimination theory of wage residuals. Under this alternative model, $s_{F t}-s_{M_{t}}=0$ while $d>0$. The empirical decomposition in equation ( 7 ) then reduces to

$$
\Delta R_{t} \approx \sigma_{t} \Delta \Phi\left(-d / \sigma_{t}\right)+\left[\Phi\left(-d / \sigma_{t}\right)-.5\right] \Delta \sigma_{t} .
$$

Whenever $\sigma_{t}$ increases, even though $d$ remains stable, the term $\Phi(-d /$

\footnotetext{
${ }^{2}$ The normal approximation is invoked only for the numerical examples in later sections. None of the analysis in this article depends on the functional form of the distribution.

${ }^{3}$ The mean of percentile rankings is not equal to the percentile rank of the mean. More precisely, McFadden and Reid (1975) show that $E_{F_{i}} \Phi\left(\left(\hat{u}-\hat{u}_{M t}\right) /\right.$ $\left.\sigma_{M_{t}}\right)=\Phi\left(\left(\hat{u}_{k_{t}}-\hat{u}_{M_{t}}\right) / \sqrt{2 \sigma_{t}^{2}}\right)$. This adjustment does not affect the argument in the article.
} 
$\sigma_{t}$ ) will increase. Thus, the empirical decomposition using the ranking method will produce the false impression that the "unmeasured skill differential" has declined (the first term is positive) while "skill price" has risen (the second term is negative) ${ }^{4}$ This effect arises because more dispersed distributions tend to bave thicker tails. As the residual wage distribution becomes more dispersed, the percentile rank of the female wage residuals (which are concentrated near the lower tail of the distribution) will rise. ${ }^{5}$ Since $\Delta \Phi\left(-d / \sigma_{t}\right)$ and $\Delta \sigma_{t}$ will be positively correlated when $d>0$, the decomposition in equation (9) is correct only in an accounting sense, and the resulting separation of "price effect" and "quantity effect" is arbitrary.

In general, the unmeasured skills model and the discrimination model may both contain an element of truth, in which case the general formula shown in equation (7) is applicable. As long as $d>0$, an increase in $\sigma_{t}$ will increase $\Phi\left(s_{F_{t}}-s_{M_{t}}-d / \sigma_{t}\right)$. Thus the measure of skill convergence using the residual decomposition methodology will tend to be upward biased.

\section{Distinguishing between the Two Models}

There are several possible reasons why the variance of the residual wage distribution has increased over the last decade in the United States:

1. The price of unmeasured skill may have risen, as emphasized by Juhn, Murphy, and Pierce.

2. Under the discrimination theory of wage differentials, $\sigma_{i} \theta_{i t}$ may be interpreted as measurement error or pricing error rather than unobserved skill. An increase in measurement or pricing errors would then increase the variance of the wage residuals. For example, pricing errors in the labor market may have increased because of the increasing complexity of work.

3. The market may have come to value a more diverse set of worker attributes as the economy becomes more complex. For example, in a simple characteristics model (e.g., Welch 1969; Rosen 1978), one can think of $\sigma_{t} \theta_{t t}$ as the inner product of a vector of characteristics and the corresponding vector of prices. If the number of valued attributes rises (i.e., the length of the vector $\theta_{i t}$ increases), and if the new attributes are not strongly negatively correlated with the existing attributes, the variance of $\sigma_{i} \theta_{i t}$ will rise. ${ }^{6}$ In this case, unlike the unidimensional skill model,

\footnotetext{
${ }^{4}$ Conversely, the mean percentile rank for female wages would fall if the male wage distribution becomes less dispersed, causing a bias in the opposite direction.

${ }^{5}$ If women had higher wages than men, their average percentile ranks in the male wage distribution would fall with an increase in the wage dispersion.

${ }^{6}$ The increase in number of valued attributes can also be interpreted as an increase in price of skills (from zero to positive). This, however, does not affect
} 
individuals with high residual wages in one year will not experience above-average wage gains when wage inequality rises. Moreover, rising skill prices can give wage convergence rather than divergence if the lower wage group has relatively more of the skills whose prices rise the most.

Some of these interpretations may be more plausible than others. The point is, a decomposition of the residual wage differential into "price effects" and "quantity effects" sheds little light on resolving the alternative interpretations. Finding that the two terms in the decomposition exercise carry definite signs implies nothing about the price or quantity of skill.

The two alternative models of residual wages are not entirely indistinguishable, however. If the unmeasured skill interpretation is correct, a rise in the price of skill should be uncorrelated with changes in the differential quantity of skill between two groups. A rise in the dispersion of the residual wage distribution should then be associated with a widening of the residual wage gap ( ince the first term in the decomposition is on average zero while the second term is negative). If the statistical interpretation proposed here is correct, the simple properties of distribution functions dictate that a rise in $\sigma_{t}$ should be associated with an increase in $\Phi\left(-d / \sigma_{t}\right)$. The two terms roughly cancel, and the residual wage gap should remain unchanged.'

The distinction between the two models can also be illustrated diagrammatically. Panel a of figure 1 depicts the "unmeasured skill" model of residual wages. The line $A A$ shows the profile of log wages against skill. Point $M$ on $A A$ is the male mean, and point $F$ is the female mean. The distance $W_{M} W_{F}$ is the gender wage gap. In this model, an increase in the price of "unmeasured skill" is represented by tilting the wage profile to $A^{\prime} A^{\prime}$. If average female skill $\left(S_{F}\right)$ remains unchanged, the gender gap widens to $W_{M} W_{F}^{\prime}$. Only when average female skill increases to $S_{F}^{\prime}$ will the gender gap remain constant. The statistical interpretation of wage residuals is represented by figure $1 b$. The line $A_{M} A_{M}$ plots male log wages by increasing order, and $A_{F} A_{F}$ plots female log wages. The wage gap, $W_{M} W_{F}$, may be due to discrimination or difference in level of skill. If we project female wages onto the male distribution, the horizontal distance $R_{H} R_{M}$ is the difference in their mean percentile ranks. When wages become more dispersed, both $A_{M} A_{M}$ and $A_{F} A_{F}$ become steeper. While the wage gap remains unchanged, the difference in mean percentile ranks, $R_{F}^{\prime} R_{M}$, falls.

the argument since the model assumes $s_{V_{j}}=s_{M_{j}}$. An increase in price of skills would have no effect on the wage differential under this assumption.

"The effect of a small increase in dispersion, $\Delta \sigma$, on the residual wage gap is equal to $(\Phi(-d / \sigma)-.5) \Delta \sigma+\sigma \Delta \Phi(-d / \sigma)$. Since $\Phi(-d / \sigma)-.5=\Phi(-d /$ 
Blau and Kahn (1992) argue that the higher price of unmeasured skill in the United States tends to increase its gender gap relative to other countries. It is interesting to note that they also find that, compared to women elsewhere, U.S. women are less disadvantaged in terms of the quantity of unmeasured skill. The unmeasured skill model offers no reason why higher prices should be associated with smaller quantity gaps. ${ }^{8}$ The statistical model, however, predicts that a negative $\left[\Phi\left(-d / \sigma_{t}\right)\right.$ - .5] $\Delta \sigma_{t}$ should be associated with positive $\sigma_{t} \Delta \Phi\left(-d / \sigma_{t}\right) .{ }^{9}$ A quick calculation on table 2 of Blau and Kahn (1992) gives a simple correlation coefficient of -.98 for a sample of seven countries.

As an illustration of the quantitative significance of the possible statistical illusion resulting from the decomposition, consider Blau and Kahn's (1993) analysis of the U.S. gender gap. They state:

Over the 1975-87 period, due to rising wage inequality, the wages of men in the lower portion of the wage distribution were falling relative to the male mean. Thus, if women's mean percentile ranking had remained at 22 , their relative wages would have declined from 60.4 to 56.8 percent of men's. In fact, however, the gender ratio increased over this period by 9.5 percentage points to 69.8 percent. Women were able to counter the impact of rising inequality by increasing their percentile in the male distribution from 22 to 31 over this period.

To infer convergence in skills from the above facts requires the assumption that percentile ranks are independent of changes in wage inequality. If one assumes instead that relative wage is independent of changes in the wage dispersion, the conclusion will be very different. When wage inequality rises, women's percentile rank will increase even if other things remain equal. For example, if the standard deviation of (raw) wages increased from .49 to .59 in this period (see Juhn et al. 1993, table 1), women's percentile ranking would increase from $\Phi(-.4 / .49)=.21$ to $\Phi(-.4 / .59)=.25$. An increase in relative wage from $60.4 \%$ to $69.8 \%$ will then raise the percentile rank to $\Phi(-.3 / .59)$ $=.31$. No appeal to counteracting movements in unobserved prices and quantities is necessary.

$\sigma)-\Phi(0) \approx \phi(-d / \sigma) d / \sigma$ and since $\Delta \Phi(-d / \sigma) \approx \phi(-d / \sigma) d / \sigma^{2}$, the two terms roughly cancel.

${ }^{8}$ Blau and Kahn also find that the gender gap in observables is smaller in the United States and that the returns to those observables are greater in the United States compared with a number of other countries. This would be a corroboration of their interpretation if unmeasured skill and the observables are positively related. However, by construction, unmeasured skill is derived from least-squares residuals, which are orthogonal to the observables.

${ }^{9}$ The $\Delta$ operator here refers to cross-country differences. 


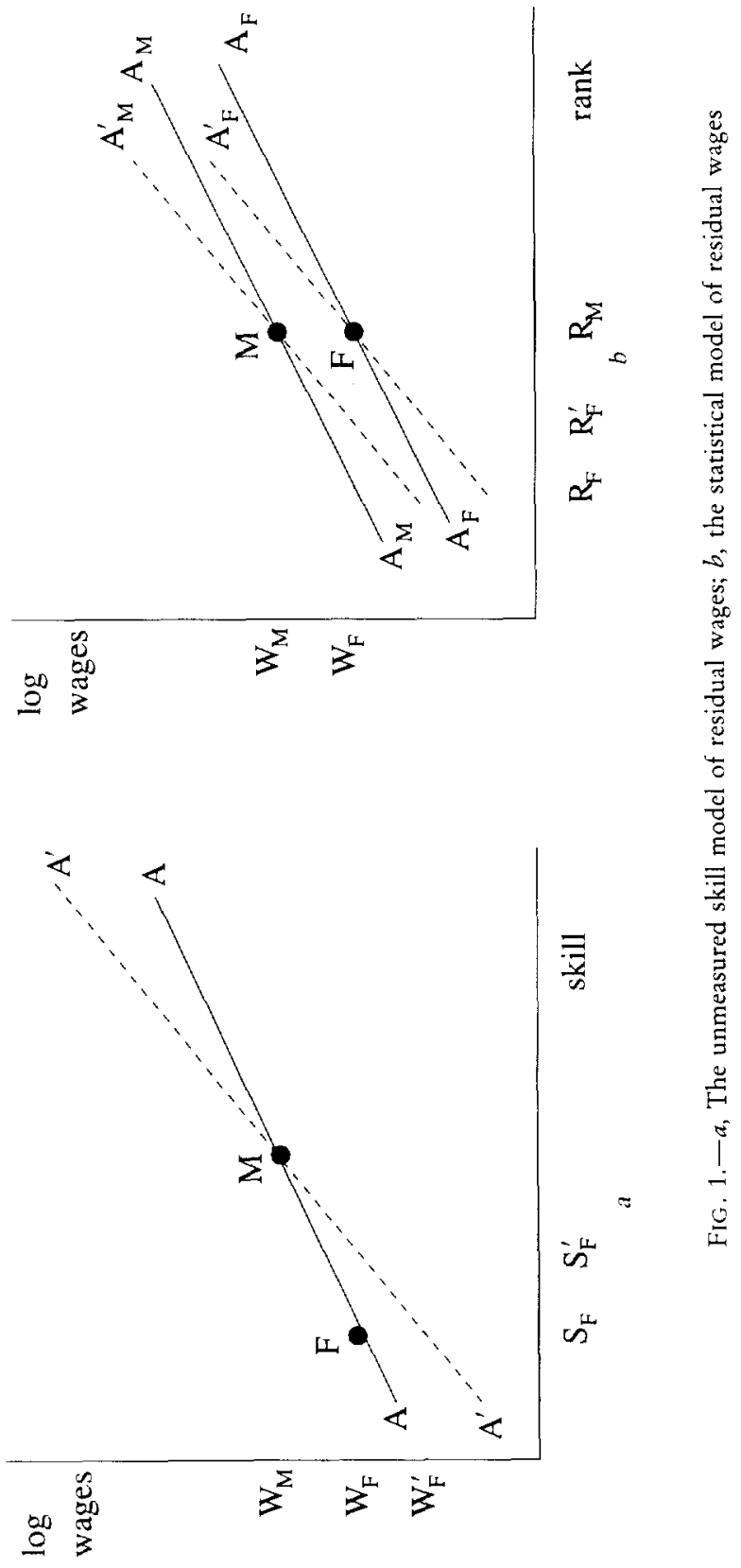




\section{Synthetic Cohorts and Panel Data}

Existing studies using the decomposition of wage residuals are mostly applied to cross-sectional data at different time periods. In that framework, "convergence in skills" can be supposed to arise from the cohort effect: new entrants to the labor market may possess a different set of skills than existing participants. However, if the wage gap is calculated for synthetic cohorts or for a panel of individuals, then-assuming the unobserved skills of each individual are fixed over time-there is a priori no reason to expect any "convergence in skills." According to the pure discrimination theory of the wage gap, in contrast, "convergence in skills" is merely a statistical artifact associated with any increase in the variance of the residual wage distribution. One should therefore expect the decomposition methodology to produce "convergence" even when there is none. The use of synthetic cohorts or panel data, together with the identifying restriction that unobserved skills are fixed over time, will then provide a possible way of resolving the two alternative interpretations of the change in residual wage gap.

More specifically, under the residual decomposition method, "convergence in skills" is given by the term

$$
\sigma_{t} \Delta \Phi\left(\left(s_{F_{t}}-s_{M t}\right)-\left(d / \sigma_{t}\right)\right) .
$$

In two cross sections, both $s_{F_{t}}-s_{M_{t}}$ and $d / \sigma_{t}$ will change, and the two are not separately identifiable. If data from synthetic cohorts or longitudinal surveys are used, one can plausibly impose the restriction that $s_{F_{t}}-s_{M t}$ is constant over time. Then, on the one hand, according to the unobserved skills theory of the wage gap (which assumes $d=0$ ), one should expect that the "convergence" term (10) is zero. On the other hand, according to the discrimination theory of the wage gap (which assumes $d>0$ ), one should expect (10) to be positive in periods when $\sigma_{i}$ has risen.

If panel data are used, the first difference in wage residuals will also provide useful information toward resolving the two alternative interpretations of the wage gap. Let $v_{i t}=u_{i t}-u_{i s}$ denote the residual wage change for individual $i$, where the residuals $u_{i t}$ and $u_{i s}$ are obtained from two separate wage regressions, one for each period. Given the general model of wage residuals in equation (4), and assuming that $\boldsymbol{\theta}_{i t}$ and $\boldsymbol{\delta}_{i t}$ are constant through time, one can write

$$
v_{i t}=\theta_{i t} \Delta \sigma_{t}
$$

Compute the difference in the mean of $v_{i t}$ between men and women:

$$
v_{H_{t}}-v_{M t}=\left(s_{H_{t}}-s_{M t}\right) \Delta \sigma_{t} .
$$


According to the unobserved skills model, $s_{F_{t}}-s_{M t}<0$ and equation (12) should be negative in a period of rising inequality. According to the discrimination model, however, $s_{t t}-s_{M t}=0$ and equation (12) should be zero.

\section{Conclusion}

The method of using percentile ranks to "decompose" the residual wage gap is useful for detecting asymmetries in the upper and lower ends of the wage distribution. To go beyond that to infer changes in unobservable prices and quantities is prone to error. If rising wage inequality is due to the rising price of some unidimensional skill, then, other things being equal, the average percentile ranks of female wages and black wages should remain stable while their average pay gaps widen. If rising inequality is due to the fact that the market comes to value a more diverse set of attributes (of which minorities and white males possess equal amounts), then, other things being equal, the average percentile rank of female wages and black wages should rise while their pay gaps remain stable. Labeling an arbitrary decomposition "price effects" and "quantity effects" will not help resolve the mystery of rising wage inequality. To establish the unmeasured skill interpretation of wage residuals would require the use of panel data. If there is a rise in the price of skill over time, individuals with high wage residuals would experience larger wage gains than those with low wage residuals. The statistical interpretation proposed here does not have such an implication.

\section{References}

Blau, Francine D., and Kahn, Lawrence M. "The Gender Earnings Gap: Learning from International Comparison." American Economic Review 82 (May 1992): 533-38.

-. "The Changing Composition of the U.S. Labor Force: Implications for Public Policy." Working paper. Urbana-Champaign: University of Illinois, June 1993.

Blinder, Alan S. "Wage Discrimination: Reduced Form and Structural Variables." Journal of Human Resources 8, no. 4 (1973): 436-55.

Goldin, Claudia, and Margo, Robert A. "The Great Compression: The Wage Structure in the United States at Mid-Century." Quarterly Journal of Economics 107 (February 1992): 1-34.

Juhn, Chinhui; Murphy, Kevin M.; and Pierce, Brooks. "Accounting for the Slowdown in Black-White Wage Convergence." In Workers and Their Wages, edited by M. Kosters, pp. 107-43. Washington, DC: AEI, 1991.

"Wage Inequality and the Rise in Returns to Skill." Journal of Political Economy 101 (June 1993): 410-42.

LaLonde, Robert J., and Topel, Robert H. "The Assimilation of Immigrants in the U.S. Labor Market." In Immigration and the Work Force: 
Economic Consequences for the United States and Source Areas, edited by George Borjas and Richard Freeman, pp. 67-92. Chicago: University of Chicago Press, 1992.

Margo, Robert A. "Explaining Black-White Wage Convergence, 19401950: The Role of the Great Compression." Industrial and Labor Relations Review 48 (April 1995): 470-81.

McFadden, D., and Reid, F. "Aggregate Travel Demand Forecasting from Disaggregated Behavior Models." Transportation Research Board Record. No. 534. Washington, DC: Transportation Research Board, 1975. Oaxaca, Ronald. "Male-Female Wage Differentials in Urban Labor Markets." International Economic Review 14 (October 1973): 693-709.

Rosen, Sherwin. "Substitution and the Division of Labor." Economica 45 (1978): $235-50$.

Welch, Finis. "A Linear Synthesis of Skill Distributions." Journal of Human Resources 4 (1969): 311-27. 